\title{
Maturity effects in futures contracts on the SAFEX market
}

\author{
Chris Motengwe* and Paul Alagidede**
}

\begin{abstract}
*Contact author: busdevelop7@gmail.com, Department of Agricultural Economics, Extension and Rural Development, University of Pretoria, South Africa

***Paul.Alagidede@wits.ac.za,Wits Business School, University of the Witwatersrand, South Africa
\end{abstract}

\begin{abstract}
This article examines maturity effects for futures contracts listed on the South African Futures Exchange (SAFEX). Three classes of derivative contracts are examined; agricultural, metals and energy futures. Estimation of the Samuelson effect is by ordinary least squares (OLS) approach using the volatility estimator in Garman and Klass (1980), Parkinson (1980) and Serletis (1992). The analysis simultaneously tests for the Samuelson effect while establishing significance of traded volume, change in open interest and bid-ask spread on intraday volatility. Multicollinearity and seasonality are incorporated to examine if maturity effects remain in the contracts. Findings are that only wheat supports maturity effects. However, white maize and silver volatility decline as time-to-maturity diminishes. The implications of the results for traders and market participants are discussed.
\end{abstract}

JEL Classification: C13, C58, G13

Keywords: Futures market; volatility; contract maturity; Samuelson hypothesis 


\section{Introduction}

The paper looks at the hypothesis that volatility in three asset classes on the futures market in South Africa tends to increase nearer to maturity. The focus is on agricultural, metals and energy contracts. Unexpected price volatility has potential to exert upward pressure on food, energy and metals prices. "Boom and bust" price patterns have characterised crises in a number of financial markets in recent years. Price volatility however, presents both challenges and opportunities for futures market participants. Samuelson (1965) hypothesised that futures sensitivity to new information and volatility both increase as maturity nears, otherwise known as the Samuelson effect. Understanding futures volatility behaviour is important in estimating initial margins, margin adequacy, hedging positions, futures risk and option prices. Besides revisiting Samuelson effects in agricultural futures, it is believed that this paper is the first study to look at maturity effects in energy or metal contracts on SAFEX. Furthermore, this paper examines maturity effects taking into account traded volume, open interest and spread in SAFEX contracts.

This study is relevant and important as it provides inputs and tools for developing trading strategies which exploit market inefficiencies and systematic anomalies deriving from maturity effects in SAFEX contracts. Characterising behaviour of contract volatility from listing to maturity is important in a number of ways. Firstly, one of the key variables in margin estimation is volatility. In Board and Sutcliffe (1991), Hedegaard (2011) and Brooks, Clare, Dalle \& Persand (2005), contract margins have a positive relationship with price volatility. Therefore, variation in volatility should be reflected in futures margins if exchange integrity and prudency is to be sustained. Secondly, hedging strategies mitigating contract risks and volatility can only be

developed if volatility patterns are known. Such strategies can be implemented by switching positions across contracts with different times to maturity, given their behaviour to expiration.

Thirdly, in accordance with Black (1976), volatility is one of the most important variables in the pricing of options. When written on contracts supporting Samuelson effects, options experience an increase in value as the probability of ending up in-the-money at maturity increases. Fourthly, volatility is an important input into any investment decision-making. Studies that include Black (1976), Pardo and Torro (2007), Devlin, Woods, \& Coates (2011), Morgan, Cotter \& Dowd 
(2012) and Tadesse, Algieri, Kalkuhl \& Von Braun (2013) all agree futures volatility is unobserved and unknown prior to making an investment. Therefore, insights into systematic volatility patterns assist in estimating risk premiums and hence the required minimum returns to justify a given investment.

The paper therefore considers an important research problem deriving from underlying commodity price shocks. Debates on competing influences of market fundamentals, seasonality and systematic market anomalies and the use of the right tools in predicting volatility have been on-going. As confirmed in Gouel (2012), volatility behaviour once again became a major focus area in the wake of extreme market movements around the time of the global financial crises. Gilbert (2010), Du, Yu, \& Hayes (2011) and Filimonov, Bicchetti, Maystre \& Sornette (2013) acknowledge that between 2003 and June 2008, food, energy, precious metals and other commodities saw increases in prices beyond $100 \%$. Particularly for South Africa, results in PwC (2012) suggest participants in commodity markets have limited tools to predict return volatility, to smoothen and sustain profitability when investing.

Findings from the study will be useful to brokers, market operators, risk managers and other market participants in optimising hedging, speculation, margin computations and option pricing. Margins derived using accurate estimates of volatility enable balancing the twin objectives of prudentiality and opportunity cost minimisation, sustaining the integrity of a futures exchange. When the Samuelson effect holds, margin levels should be increased as the contract nears maturity. Accurate forecasting of volatility behaviour is pivotal in developing risk-mitigation strategies on the futures market. The usefulness of the results to market participants derives in providing the answer to whether volatility increases as the contract delivery date nears. Traders are concerned about high volatility as risk premiums increase proportionately with higher price fluctuations. Hedgers would need to proportionately adjust hedge ratios as price fluctuations vary. As speculators trade volatility, characterising price change behaviour enables capturing arbitrage opportunities.

In this study, more contracts have been added to the analysis extending from the maturity effects study by Viljoen (2004), who looked at SAFEX white and yellow maize and wheat, but did not 
look at energy and metals contracts. Furthermore, a novel testing strategy is used in the current investigation, extending on previous methodologies while accounting for multicollinearity and seasonality. It should be noted that literature has obtained different results for commodities in different asset classes. It is therefore important to know whether there could be specific patterns on SAFEX leading to support for maturity effects, across commodity classes, within a specific asset class, or depending on the market of primary listing of a contract.

Literature also generally agrees, including in Castelino and Francis (1982), Milonas (1986) and Kolb (1997), that futures and spot prices converge at maturity leading to higher sensitivity to new information just before contract expiration. South Africa has traditionally been a major producer of various minerals from which metal products are manufactured. The country also produces its own fuel, having the world's biggest synfuel (SASOL Pty. Ltd.) plant converting coal to petroleum products (Eberhard, 2011). Investigating more asset classes important to South Africa is essential given that many economic players are impacted by developments in markets in which these commodities are traded. Agricultural futures, by way of their unique harvesting and growing cycles, are known to have distinct seasonal patterns quite apart from the metal and energy commodity classes.

In terms of methodology for investigating contract maturity effects, this article accounts for the impact of traded volume, open interest and the bid - ask spread. This approach extends from Kenourgios and Katevatis (2011), who included the two other explanatory variables, leaving out the bid - ask spread in their estimations. Further, the study accounts for both seasonality and multicollinearity, which is not easy to achieve when applying non-parametric analysis, as employed in Viljoen (2004). It should be noted that the Viljoen (2004) study did not find support for maturity effects in the wheat contract, contrary to findings in this thesis. Owing to differences in both methodology and findings, the current study brings new perspectives to maturity effects literature.

Maturity effects in SAFEX white maize, yellow maize and wheat are investigated in Viljoen (2004) using non-parametric approaches. In that study, the Samuelson hypothesis was confirmed in white maize, but not in yellow maize and wheat. In this paper, maturity effects are examined 
using parametric approaches. The results in this paper are that only wheat on SAFEX supports the Samuelson effect going by the various tests in literature or using extensions to previously used analysis. The paper is organized as follows. Section 2 provides literature and findings by selected authors on maturity effects. Section 3 presents the methodology and data for this study. In Section 4, research findings are presented. Section 5 describes the robustness analysis carried out to further validate key findings. Section 6 concludes the paper.

\section{Literature Review}

Tests for maturity effects in literature have generated mixed outcomes (Liu, 2014). Segall (1956) and Telser (1956) first formally acknowledged the tendency for increased financial asset volatility as maturity nears, while Samuelson (1965) put forward the hypothesis to this effect. Samuelson (1965) posited that as a contract gets nearer to maturity, variability in prices rises. In this section, we critically review a number of papers that investigated the Samuelson hypothesis. Firstly, the paper looks at evidence on differences in findings between commodities and empirical methodologies used by the leading studies. Literature appears to have more limited evidence of support for the Samuelson hypothesis in certain asset classes and Kalev and Duong (2008) have included metals, financial futures and currencies, as such non-supporting assets. No

evidence of support for maturity effects is also found in five currency futures in Grammatikos and Saunders (1986). Bessembinder, Coughenour, Seguin \& Smoller (1996) and Duong and Kalev (2008) could not find evidence of support for Samuelson effects in treasury bond futures, index futures, and metal futures. Further, a number of other studies have also suggested maturity effects are not common in financial futures (Allen \& Cruickshank, 2000; Duong \& Kalev, 2008; Galloway \& Kolb, 1996).

Early work in Rutledge (1976) found support in silver and cocoa but not in wheat and soybean oil. Bessembinder et al. (1996) developed a framework for predicting if a given asset would support the Samuelson hypothesis. In the first place, they found that the clustering of information nearer to the delivery date was not a necessary condition for support of maturity effects. The precondition for support seemed to be the existence of a predictable temporary component in spot prices, and markets for real assets rather than financial assets were more likely to have this 
element. An alternative condition to be satisfied was the negative covariation between spot returns and changes in the slope of the futures term structure. They then concluded support would occur in markets where spot prices were mean-reverting and the reversion was linked to variation in the cost of carrying inventory. Going by this thread of literature, empirical evidence showed that markets for agricultural contracts and crude oil supported maturity effects. Additional work in Brooks (2012) sought to provide further clarity on how to predict possible support by diverse assets. The reason for differences in support, according to Brooks (2012), has to do with whether a given asset behaves consistently with the carry arbitrage phenomenon. Thus, the degree for support for maturity effects is linked to the degree to which the carry arbitrage hypothesis is not supported by the same asset. Carry arbitrage in Brooks (2012) is a theoretical phenomenon in which an underlying asset is purchased with borrowed money, and a hedge created by way of a short forward position.

Differences in approaches for examining maturity effects have largely to do with the choice of measure of volatility used by diverse studies. Some studies have used the daily high - low range for calculating volatility, while others used squared daily close-to-close returns. Parkinson (1980) showed the former to be five times more efficient than the latter, while Andersen and Bollerslev (1998) confirmed efficiency improvements when using the latter. Some studies have used parametric techniques, particularly GARCH extensions, to generate volatility measures. However, most financial data has shown no support for the normal distribution, on which these approaches should be grounded. Studies in literature demonstrating evidence of financial assets not supporting normality are Cornew, Town \& Crowson (1984), Warshawsky (1989), Kofman (1992), Venkateswaran, Brorsen \& Hall (1993) and Broussard and Booth (1998).

Galloway and Kolb (1996) suggest sensitivity to new information increases nearer maturity as spot and futures prices converge, hence the occurrence of maturity effects. In Castelino and Francis (1982), maturity effects are accepted for CBOT soybean and wheat futures for data from 1960 through 1971. In Anderson (1985), data from 1966 through 1980 on 8 commodities is used in maturity-effect estimations. CBOT, KCBT, CME and COMEX futures contracts were 
examined finding five commodities with Samuelson effects including wheat, oats, soybeans, live cattle and cocoa.

Maturity effects in agricultural, financial and metal futures are investigated in Milonas (1986) and Milonas (1991). The studies examine 5 agricultural, 3 financial and 3 metal futures contracts. Out of the 11 futures contracts, 10 supported the Samuelson hypothesis (4 agricultural, 3 financial and 3 metals contracts). Evidence was also provided that far-from-maturity futures contracts were reacting less strongly to information than nearer-maturity contracts. Serletis (1992) finds support for the Samuelson hypothesis in NYMEX energy contracts in data from 1987 through 1990. Khoury and Yourougou (1993) examined 6 agricultural futures on the Winnipeg Commodity Exchange (WCE) with data from 1980 to 1989. Price data used includes WCE daily high, low, open, and close levels for canola, rye, feed barley, feed wheat, flaxseed and oats. All futures contracts supported calendar seasonality effects as well as maturity effects using OLS regression estimation. Goodwin and Schnepf (2000) confirm the Samuelson hypothesis in maize but not wheat in US futures markets using weekly data. GARCH estimations and the VAR approaches used find seasonality, crop growing conditions and the maturity effect as key determinants of price volatility.

In Chatrath et al. (2002) there is support for the Samuelson effect for maize but not wheat. The analysis uses augmented GARCH extensions with control for seasonality and maturity effects. Daal, Farhat and Wei (2003) find support for maturity effects by agricultural and energy contracts listed in London, Sydney, Tokyo, Winnipeg and the US over the period 1960 through 2000. In a study involving 20 futures contracts from four categories (agricultural, energy, metals, financial), Duong and Kalev (2008) confirmed the Samuelson effect for agricultural futures, but not for metals, energy and financial futures. Data in the study was from 1996 to 2003 . A different study by Kalev and Duong (2008) investigated the Samuelson effect in 14 futures using data from 1996 through 2003. Agricultural contracts supporting the Samuelson hypothesis included maize, soybean, soybean oil, soybean meal and wheat. The maturity effect was not supported by energy, metal and financial futures. Our study includes three of the contracts examined in Kalev 
and Duong (2008), that is, corn or maize, wheat and crude oil. While their paper looked at the gold contract, this paper looks at silver.

Maturity effects were examined in Karali and Thurman (2010). Futures contracts studied were maize, soybeans, wheat and oats, all on the North American grain futures markets. Strong evidence of the Samuelson effect in contracts studied is confirmed. Kenourgios and Katevatis (2011) examined two leading Greek indices on the Athens Derivatives Exchange (ADEX) finding support for the Samuelson hypothesis in both of them. OLS and GARCH approaches were used with data from 1999 through 2007.

Finally, Kenourgios and Katevatis (2011) have incorporated market liquidity and seasonalityrelated variables into maturity effect estimations. Their idea was to find out if these variables were more important in explaining volatility than time-to-maturity. A positive link between volatility and traded volume and a negative link between volatility and open interest were confirmed. For the two financial indices examined, inclusion of volume and open interest in the maturity effect relation diminished the significance of the coefficient for time-to-maturity. This paper has looked at this literature and gone further to consider the bid-ask spread, another key liquidity variable in financial markets.

\section{Methodology and Data}

\section{Empirical Methodology}

Estimation of maturity effects in this paper is by ordinary least squares (OLS) with time-tomaturity as one of the explanatory variables to contract volatility. To derive return volatility, an

estimator generated from daily high-low prices is used. This approach is similar to Garman and Klass (1980), Parkinson (1980) and Serletis (1992). The specification of volatility follows the relation

$$
V A R_{t}=\frac{\left(\ln H_{t}-\ln L_{t}\right)^{2}}{4 \ln 2}
$$


Where $H_{t}$ and $L_{t}$ are high and low prices, respectively. In Serletis (1992), simple regression estimation has been used to check for the Samuelson effect as follows:

$$
V A R_{t}=\alpha_{0}+\alpha_{1} \ln T T M_{t}+\varepsilon_{t}
$$

Where $V A R_{t}$ is the volatility of futures prices or returns derived from daily high and low prices in Equation (1). Time-to-maturity on day $t$ is captured in $T T M_{t}$ which decreases from the time a contract is listed to its maturity (when it becomes zero), and a random error is represented by $\varepsilon_{t}$.

Similar to Kenourgios and Katevatis (2011), traded volume and open interest are introduced into the relations testing for the maturity effect using the following relation:

$$
V A R_{t}=\beta_{0}+\beta_{1} \ln T T M_{t}+\beta_{2} \ln \operatorname{Vol}_{t}+\beta_{3} \Delta \ln O I_{t}+u_{t}
$$

Time-to-maturity, traded volume and change in open interest are captured respectively in $\operatorname{lnTTM}_{t}, \ln V o l_{t}$ and $\Delta \ln \mathrm{OI}_{t}$. The paper makes an addition to literature by incorporating the bid-ask spread, an important liquidity variable in financial markets. This paper follows Corwin and Schultz (2012) who make use of daily high and low prices to derive the bid-ask spread. Roll (1984) postulates that the bid-ask spread is a reflection of transaction costs which themselves influence liquidity in futures markets. Corwin and Schultz (2012) acknowledge their bid-ask spread estimator is fairly easy to generate and use. The key relation for deriving the estimator is:

$$
\left[\ln \left(H_{t}^{0} / L_{t}^{0}\right)\right]^{2}=\left[\ln \left(\frac{H_{t}^{A}(1+S / 2)}{L_{t}^{A}(1-S / 2)}\right)\right]^{2}
$$

Where the actual daily high and low prices are captured in $H_{t}^{A}\left(L_{t}^{A}\right)$, and $H_{t}^{0}\left(L_{t}^{0}\right)$ are observed daily high and low prices, on trading day $t$. It is explained in Corwin and Schultz (2012) that the difference between observed prices for buys and actual values is a spread element amounting to $(\mathrm{S} / 2) \%$. In the same way, observed prices for sells are lower than actual values by the spread 
element of (S/2)\%. The bid-ask spread in Corwin and Schultz (2012) was defined by the simplified relation:

$$
S=\frac{2\left(e^{\alpha}-1\right)}{1+e^{\alpha}}
$$

Furthermore, simplification of the equations gives:

$$
\alpha=\frac{\sqrt{2 \beta}-\sqrt{\beta}}{3-2 \sqrt{2}}-\sqrt{\frac{\gamma}{3-2 \sqrt{2}}}
$$

Parameters $\beta$, and $\gamma$ are elaborately defined in Corwin and Schultz (2012). The relation for $\beta$ is:

$$
\beta=E\left\{\sum_{j=0}^{1}\left[\ln \left(\frac{H_{t+j}^{0}}{L_{t+j}^{0}}\right)\right]^{2}\right\}
$$

The parameter $\gamma$ can be estimated using the relation

$$
\gamma=\left[\ln \left(\frac{H_{t, t+1}^{0}}{L_{t, t+1}^{0}}\right)\right]^{2}
$$

In the above relation, $H_{t, t+1}$ is the high price for the 2 days $t$ and $t+1$ and $L_{t, t+1}$ is the low price during the 2 days $t$ and $t+1$. Bid-ask spread estimates for 2-day periods are used in Corwin and Schultz (2012) to derive average monthly spreads.

The next step in this paper is to expand on the relation in Equation (3). Using the series for the bid-ask spread in Equation (5), the paper estimates:

$$
V A R_{t}=\beta_{0}+\beta_{1} \ln T T M_{t}+\beta_{2} \ln \operatorname{Vol}_{t}+\beta_{3} \Delta \ln O I_{t}+\beta_{4} S P_{t}+\zeta_{t}
$$


Where $S P_{t}$ is the bid-ask spread series for each contract. This brings into literature an extension to the relation introduced by Kenourgios and Katevatis (2011), which did not include the bid-ask spread. Given that trading-related variables are correlated, Equation (9) could have multicollinearity problems. For this reason, the paper makes provision for such adverse outcome thus improving the specification of the above relation.

In this process, the analysis explores the relationship between change in open interest and traded volume. Chamberlain (1989) used the following relation

$$
\operatorname{Ln} \Delta O I_{t}=\alpha_{0}+\alpha_{1} \operatorname{LnVol}_{t}+\varepsilon_{1, t}
$$

In the above $\alpha_{1}$ provides the extent of influence of changes in traded volume on change in open interest. Residuals $\varepsilon_{1, t}$ are saved to become a regressor in the next relation estimating the bid-ask spread.

$$
S P_{t}=\alpha_{0}+\alpha_{1} \ln \mathrm{Vol}_{t}+\hat{\varepsilon}_{1, t}+\varepsilon_{2, t}
$$

Where $S P_{t}$ is the spread as defined by the estimator in Corwin and Schultz (2012). To account for multicollinearity in Equation (9), change in open interest and spread are replaced by their residuals in the modified relation as follows:

$$
V A R_{t}=\beta_{0}+\beta_{1} \ln T T M_{t}+\beta_{2} \ln \operatorname{Vol}_{t}+\beta_{3} \hat{\varepsilon}_{1, t}+\beta_{4} \hat{\varepsilon}_{2, t}+v_{t}
$$

Proxies for $\ln \Delta O I_{t}$ and $S P_{t}$ are respectively, $\hat{\varepsilon}_{1, t}$ and $\hat{\varepsilon}_{2, t}$.

Finally, seasonality at daily and monthly levels has been taken into account to model volatility and the residuals (from the seasonality relation) have been taken as the new volatility series to replace that used in Equation (12). The respective relations used are elaborately outlined in equations (14) and (15) below. 


\section{Data}

End of day futures trade close prices, daily high and low prices as well as daily traded volume and open interest for white maize, yellow maize, wheat, silver and WTIO crude have been used. Daily data was collected through Thompson Reuters and DataStream for various periods depending on respective contract listing. Daily data, rather than monthly data were used for a number of reasons. More information is provided by daily than monthly data while avoiding the noise associated with high-frequency data. It is also worth noticing that the bulk of the activity on SAFEX takes place in the nearest-to-maturity contracts. The other contracts have fairly low liquidity levels making them substantially different from the nearest-to-maturity contracts. In this study, time-to-maturity embodied in $T T M_{t}$ decreases daily and using monthly data would also have meant excluding a lot of critical information to this type of enquiry. In using daily data, the study therefore followed approaches in seminal works in this area of study including Kalev and Duong (2008) and Brooks (2012). This approach also captures all the maturities for each contract that occurred in the nearest-to-maturity contract within the sample period. Returns were calculated using the relation

$$
R_{t}=100 * \ln \left(P_{t} / P_{t-1}\right)
$$

Where $R_{t}$ is the futures contract return and the price and lagged price series are respectively given in $P_{t}$ and $P_{t-1}$. Prices are expressed in Rands (the South African currency) per ton, and returns are expressed in percentage terms.

Contract specifications and maturity months for futures in this study are provided in Table 1. Agricultural commodity contracts have maturities in March, May, July, September and December. Energy and metals contracts mature in March, June, September and December. SAFEX trading hours are from 9.00 am to 12.00 pm during business days.

[Please Insert Table 1 about here] 
In Figure 1, the graphs for each contract show the price and returns series from the beginning of each contract's sample to about December 2014. Peak maize and wheat prices around mid-2008 coincide with the global economic downturn. For white and yellow maize, an additional notable peak in prices (beyond R3,000.00 per ton) was recorded in early 2014. The high prices were attributable to globally tight supply conditions compounded by poor earlier rainfall in South Africa. White and yellow maize prices subsequently collapsed to a trough below R2,000.00 per ton around harvest time (about mid-2014) before climbing gradually upwards.

\section{[Please Insert Figure 1 about here]}

Silver and West Texas Intermediate Oil (WTIO) have primary listings on Chicago Mercantile Exchange (CME) in the USA. This means these contracts simultaneously trade on SAFEX and CME in Rands and US Dollars respectively. As such, prices for these contracts are strongly related with international levels. Silver prices have been flat since listing before declining marginally in the second half of the graph. WTIO contract prices on SAFEX have been gradually rising since listing only to start falling significantly in the second half of 2014.

Further, summary statistics are provided in Table 2. The descriptive statistics are given in panels $\mathrm{A}$ and $\mathrm{B}$, the former based on close-to-close returns and the latter calculated from the volatility series generated similar to Parkinson (1980).

\section{[Please Insert Table 2 about here]}

In Panel A, only silver has negative mean returns suggesting a decline in the price series over the sample period. Indeed, metal prices have been depressed in South Africa in recent years. Silver returns also have the highest daily standard deviation (2.6130). Wheat has the highest daily mean returns of $0.0823 \%$. In Panel B, all the minimum volatility levels are zero, consistent with the theoretical requirement that volatility should be positive. The number of observations is different for each contract, as are sample sizes, as depicted in Table 1. The Parkinson (1980) volatility estimator has the highest daily variability in the white maize contract, with standard deviation of 0.0005. All-in-all, mean volatility levels are very close to zero for all contracts. 


\section{Results and Discussion}

Firstly, we look at whether contracts support the Samuelson effect using ordinary least squares estimation. Table 3 gives the results of the tests using Equation (2).

[Please Insert Table 3 about here]

Here we make use of daily high and low prices to generate the volatility estimator in Equation (1). In this estimation, yellow maize and wheat support the maturity effect at $1 \%$ level of significance while silver has a positive and significant coefficient at $10 \%$ level, suggesting volatility declines as time-to-maturity decreases.

We present the analysis for Equation (9) in Table 4. Traded volume, open interest and bid-ask spread are each introduced in stages, finding influences of respective liquidity variables on volatility and time-to-maturity. Three panels have been used to present the results. Panel A gives the estimation explaining volatility using time-to-maturity and traded volume. For Panel B, volatility is expressed in terms of time-to-maturity, traded volume and change in open interest. Panel $\mathrm{C}$ additionally brings bid-ask spread to the analysis to complete the estimation envisaged in Equation (9).

[Please Insert Table 4 about here]

In Panel A, evidence of the Samuelson effect is shown at $1 \%$ level for yellow maize and wheat. There is no support for the maturity effect in white maize and WTIO while volatility in silver actually decreases with diminishing time-to-maturity. An investigation was also conducted into the support for the mixture of distributions hypothesis $(\mathrm{MDH})$, which suggests a direct relation between volatility and traded volume. MDH was found to hold in contracts inclusive of white maize, yellow maize, wheat and silver. Results for these contracts are in agreement with Epps and Epps (1976) who first proposed the MDH, also later supported by findings in Bessembinder and Seguin (1993) and Andersen (1996). Neither volume nor time-to-maturity has explanatory power on the volatility of the WTIO contract. 
In Panel B of Table 4, traded volume is significant at $1 \%$ level in explaining volatility in white maize, yellow maize, wheat and silver. Change in open interest has insignificant explanatory power for white maize, yellow maize, wheat, silver and WTIO crude. Yellow maize and wheat remain in support of the Samuelson effect after inclusion of change in open interest in Panel B. Findings on open interest in Kyle (1985) and Madarassy (2003) have been asset return volatility has a significant relation with open interest. Open interest has been acknowledged as a possible proxy for market depth in Madarassy (2003) ${ }^{\mathrm{i}}$. Bessembinder and Seguin (1993) found an inverse relationship between volatility and market depth.

Bid-ask spread is introduced in Panel C. In this panel, both traded volume and bid-ask spread have a positive significant relationship at $1 \%$ level with white maize, yellow maize, wheat and silver. Yellow maize and wheat still support the Samuelson effect while silver volatility declines with decreasing period to maturity. Inclusion of all 3 liquidity variables in Equation (9) does not diminish maturity effects in yellow maize and wheat. In all 3 panels examined, white maize and WTIO have insignificant volatility changes as contract maturity approaches.

Looking at liquidity variables in Equation (9), it was necessary to address multicollinearity in the case that it existed. Given possible relationships among explanatory variables, the next step was to construct a table of cross-correlation coefficients. There is evidence of significant crosscorrelations between volume and change in open interest for white maize, wheat and WTIO crude, as shown in Table 5. Significant positive cross-correlation between traded volume and bid-ask spread is observed in white maize, wheat and silver. Change in open interest and bid-ask spreads are significantly positively correlated in the case of white maize and yellow maize. Cross-correlations among explanatory variables in Equation (9) confirm there is need to account for multicollinearity.

[Please Insert Table 5 about here]

Iterative regressions in equations (10) and (11) were estimated generating the residuals series from relations of change in open interest and bid-ask spread, respectively denoted as $\hat{\varepsilon}_{1, t}$ and $\hat{\varepsilon}_{2, t}$. Equation (12) is the estimated model with results presented in Table 6. 
[Please Insert Table 6 about here]

Findings show that yellow maize and wheat support maturity effects at $1 \%$ significance level after accounting for multicollinearity. Residuals of change in open interest $\left(\hat{\varepsilon}_{1, t}\right)$ have no significance in explaining volatility for any of the 5 contracts.

\section{Seasonality and maturity effects}

Milonas (1986) and Choi and Longstaff (1985) suggest the Samuelson effect has secondary impact subordinate to seasonality. We attempt to filter out seasonality in futures contracts while determining maturity effects in Table 7.

To account for seasonality, the following relation is used:

$$
V A R_{t}=\alpha+\sum_{i=2}^{5} \delta_{i} D_{i, t}+\sum_{m=2}^{12} \theta_{m} M_{m, t}+\xi_{t}
$$

Daily and monthly dummies are given by $D_{i, t}$ and $M_{m, t}$ respectively. Residuals series $\xi_{t}$, is saved as the new volatility series $n v_{t}$. The following regression is then estimated in Table 6:

$$
n v_{t}=\beta_{0}+\beta_{1} \ln T T M_{t}+\beta_{2} \ln \operatorname{Vol}_{t}+\beta_{3} \hat{\varepsilon}_{1, t}+\beta_{4} \hat{\varepsilon}_{2, t}+\eta_{t}
$$

Findings on this estimation provide evidence that wheat still supports the Samuelson hypothesis after accounting for daily and monthly seasonality. White maize and silver have a significant coefficient for the time-to-maturity term, but with a positive sign. Both of these contracts therefore experience lower volatility as maturity nears. A key observation is that inclusion of seasonality has not affected support for maturity effects in wheat but that which was earlier detected in yellow maize.

[Please Insert Table 7 about here]

Findings in this study are in disagreement with those of Viljoen (2004) who found support for the Samuelson hypothesis in white maize, but not in yellow maize and wheat using data from 
1997 to 2003. Differences in findings are partly attributable to the different timeframes over which data was sampled. Approaches used in the two studies are also not similar. To the extent that the metals and energy classes do not support the Samuelson hypothesis, results from this study are in agreement with those from Kalev and Duong (2008).

\section{Conclusions}

Maturity effect estimations are carried out in this paper using five futures contracts in the agricultural, metals and energy categories. The Samuelson hypothesis suggests volatility increases as time-to-maturity diminishes (Samuelson, 1965). Following Kenourgios and Katevatis (2011), the paper looked at the joint effect of traded volume, change in open interest and time-to-maturity on return variability. An extension was introduced to additionally include bid-ask spread as a liquidity explanatory variable. By replacing change in open interest and the bid-ask spread with respective residuals, estimation of maturity effects took account of multicollinearity, to give better specified results. After these adjustments, yellow maize and wheat showed evidence of support for maturity effects. Finally, seasonality was accounted for in the robustness analysis finding daily and monthly seasonality not affecting maturity effects in wheat. Yellow maize no longer supported maturity effects after taking into account seasonality. WTIO crude oil has shown no support for maturity effects at all, while white maize and silver volatility decline as time-to-maturity decreases. Findings in this paper are of interest to a range of market participants in-so-far as contract volatility is an input in pricing futures or options, hedging, speculation and setting margins on the SAFEX market. Margins for wheat should be increased proportionately as the contract approaches maturity in the months of March, May, July, September and December.

It is argued in Kuruppuarachchi (2015) that trading rules consistently profitable do not exist in efficient markets. Systematic behaviour showing patterns that can be exploited for financial gain or for hedging are a reflection of market inefficiency. Support for the Samuelson effect is a noteworthy anomaly that can be exploited in trading and hedging strategy development. In the Black - Scholes formula, and following from Black (1976), option value increases (either call or put) with higher volatility levels. This means that the ability to predict volatility levels places an 
investor in a profitable position (see also Bakshi and Madan (2000)). Furthermore, the strategy in Brenner, Ou and Zhang (2006) trades volatility change, which linearly corresponds to change in value of the proposed "at-the-money-forward straddle". This means the value of a SAFEX wheat call increases from contract listing till maturity, suggesting a long call investment is potentially profitable in this case. For white maize and silver, it is more strategic to invest in the short call towards maturity.

On SAFEX, wheat experiences an increase in volatility as maturity nears and hence a delta neutral position should be more difficult to achieve as changes in volatility make traders vulnerable. The reverse scenario applies to white maize and silver, whose volatility reduces as maturity nears. A possible strategy is to buy and hold wheat options in anticipation of the increase in value till maturity, where the position is lifted. Since the purchase price is relatively lower, an at-the-money call can be bought, for example, two months before maturity. ${ }^{\text {ii }}$ On SAFEX, contract maturity occurs at $12 \mathrm{hrs} 00$ on the sixth last business day of the contract expiry month. On the other hand, because of decreasing volatility till maturity, the value of white maize and silver options is bound to decrease as maturity approaches. In this case, a prudent strategy is to sell white maize and silver options, having higher chances of ending up out-of-the-money, allowing the option writer to earn the full premium paid.

Furthermore, Johnson (1998) explained how futures traders may build investment strategies using the Samuelson effect. To keep volatility to a minimum, the longest dated contracts are traded. For contracts where price volatility is unrelated to time-to-maturity, it was suggested traders initiate a futures position in the most convenient contract, than any presently trading, doing away with avoidable roll-overs. In this study, contracts with volatility not related to timeto-maturity are yellow maize and crude oil, making them suitable for this application.

Derivative market positions are susceptible to volatility risks that manifest in unexpected change in value. Volatility swaps in the form of a forward or futures contract on realized or implied volatility have traditionally been used to manage these risks. Volatility swaps allow trading volatility of an asset directly, forward contracting the future realised volatility of an underlying asset. Javaheri, Wilmott \& Haug (2004) explained that a volatility swap gives a payoff at 
maturity equal to the difference between realized volatility during the swap period and that which was anticipated. ${ }^{\text {iii }}$ Speculators trading volatility benefit from its increase. Kalev and Duong (2008) provided evidence that the relationship between volatility and time-to-maturity can be applied to hedging decision-making. By switching positions among contracts with different times to maturity, hedging strategies can be set up using findings from this study. Participants holding a physical or underlying futures position may need to hedge the risk using for example, a straddle option, similar to Brenner, Ou and Zhang (2006). This is typically the case for silo facility owners holding their own physical grain stocks leading up to maturity in the futures contract.

Maturity effects findings in Brooks (2012) are that contracts supporting the Samuelson hypothesis generally do not support the carry arbitrage phenomenon. Supported by a theoretical construct, carry arbitrage entails the combination of "carrying" an underlying asset purchased using borrowed funds, and hedging the position with a short forward or futures. Assets supporting carry arbitrage in Brooks (2012) included metal contracts, debt, stock indices and foreign exchange futures. Going by this literature, borrowed funds can be used to invest in long positions in contracts not supporting maturity effects over the period leading up to maturity. These investments are hedged with short futures positions lifted at maturity. This approach is recommended for SAFEX yellow maize and crude oil. In the case of assets supporting maturity effects, the reverse of carry arbitrage is applicable. This entails selling an asset, investing the proceeds, and then hedging the risk with a long futures position. The reverse arbitrage strategy is suitable in the case of the SAFEX wheat contract.

Volatility is a major input in estimating margins. Higher volatility levels are matched by higher margins set by the clearing house. Where volatility is flat during the period to maturity (the case of yellow maize and crude oil), more or less similar daily margins are prudent. Using this logic, margins for SAFEX wheat should be higher as contract maturity approaches. An outline is provided in SAFCOM (2013) on the JSE and SAFEX methodology for calculating margins. The return calculated using the maximum anticipated daily upward or downward movement is the initial margin requirement. This is actually a measure of volatility. As volatility increases, so will 
margins on SAFEX. White maize and silver should therefore have lower margins in the run-up to contract maturity.

i Market depth is defined in Madarassy (2003) as order flow capable of moving financial asset prices by one unit. ii Contract maturities occur on SAFEX in the months of March, May, July, September and December.

iii These products became popular in US markets in the aftermath of the Long Term Capital Management financial

crisis.

\section{Acknowledgements}

The authors are grateful for financial support from the Bradlow Foundation under the University of the Witwatersrand's Bradlow Scholarship programme. Comments received at the Wits Business School's May 2015 Colloquium assisted in developing the first draft. Participants at the 
International Interdisciplinary Business-Economics Advancement Conference (IIBA 2015 Las Vegas, USA) contributed with useful comments to the earlier version of the paper. All errors remain our own.

\section{References}

ALLEN, D. \& CRUICKSHANK, S. 2000. Empirical Testing of the Samuelson Hypothesis: An Application to Futures Markets in Australia. Singapore and the UK Working paper, Edith Cowan University.

ANDERSEN, T. G. 1996. Return volatility and trading volume: An information flow interpretation of stochastic volatility. The Journal of Finance, 51, 169-204.

ANDERSEN, T. G. \& BOLLERSLEV, T. 1998. Answering the skeptics: Yes, standard volatility models do provide accurate forecasts. International economic review, 885-905.

ANDERSON, R. W. 1985. Some determinants of the volatility of futures prices. Journal of Futures Markets, 5, 331-348.

BAKSHI, G. \& MADAN, D. 2000. Spanning and derivative-security valuation. Journal of Financial Economics, 55, 205-238. 
BESSEMBINDER, H., COUGHENOUR, J. F., SEGUIN, P. J. \& SMOLLER, M. M. 1996. Is there a term structure of futures volatilities? Reevaluating the Samuelson hypothesis. The Journal of Derivatives, 4, 45-58.

BESSEMBINDER, H. \& SEGUIN, P. J. 1993. Price volatility, trading volume, and market depth: Evidence from futures markets. Journal of financial and Quantitative Analysis, 28, 21-39.

BLACK, F. 1976. The pricing of commodity contracts. Journal of financial economics, 3, 167179.

BOARD, J. \& SUTCLIFFE, C. 1991. Information, volatility, volume and maturity: An investigation of stock index futures. Review of Futures Markets, 9, 532-549.

BRENNER, M., OU, E. Y. \& ZHANG, J. E. 2006. Hedging volatility risk. Journal of Banking \& Finance, 30, 811-821.

BROOKS, C., ClARE, A., DALlE MOLLE, J. W. \& PERSAND, G. 2005. A comparison of extreme value theory approaches for determining value at risk. Journal of Empirical Finance, 12, 339-352.

BROOKS, R. 2012. Samuelson hypothesis and carry arbitrage. The Journal of Derivatives, 20, 37-65.

BROUSSARD, J. P. \& BOOTH, G. G. 1998. The behavior of extreme values in Germany's stock index futures: An application to intradaily margin setting. European Journal of Operational Research, 104, 393-402.

BUENO, J. A., DE OLMO, A. M. R., IVORRA, B. \& DE MASTER, T. D. F. 2012. Trading the volatility skew of the options on the $\mathrm{S} \& \mathrm{P}$ index.

CASTELINO, M. G. \& FRANCIS, J. C. 1982. Basis speculation in commodity futures: The maturity effect. Journal of Futures Markets, 2, 195-206.

CHAMBERLAIN, T. W. 1989. Maturity effects in futures markets: Some evidence from the city of London. Scottish Journal of Political Economy, 36, 90-95.

CHATRATH, A., ADRANGI, B. \& DHANDA, K. K. 2002. Are commodity prices chaotic? Agricultural Economics, 27, 123-137.

CHOI, J. W. \& LONGSTAFF, F. A. 1985. Pricing options on agricultural futures: An application of the constant elasticity of variance option pricing model. Journal of Futures Markets, 5, 247-258.

CORNEW, R. W., TOWN, D. E. \& CROWSON, L. D. 1984. Stable distributions, futures prices, and the measurement of trading performance. Journal of Futures Markets, 4, 531-557. 
CORWIN, S. A. \& SCHULTZ, P. 2012. A simple way to estimate bid-ask spreads from daily high and low prices. The Journal of Finance, 67, 719-760.

DAAL, E., FARHAT, J. \& WEI, P. 2003. Reexamining the maturity effect using extensive futures data. University of New Orleans, Department of Economics and Finance.

DEVLIN, W., WOODS, S. \& COATES, B. 2011. Commodity price volatility. Economic Roundup, 1.

DU, X., YU, C. L. \& HAYES, D. J. 2011. Speculation and volatility spillover in the crude oil and agricultural commodity markets: A Bayesian analysis. Energy Economics, 33, 497503.

DUONG, H. N. \& KALEV, P. S. 2008. The Samuelson hypothesis in futures markets: An analysis using intraday data. Journal of Banking \& Finance, 32, 489-500.

EBERHARD, A. 2011. The future of South African coal: Market, investment and policy challenges. Program on Energy and Sustainable Development, 1-44.

EPPS, T. W. \& EPPS, M. L. 1976. The stochastic dependence of security price changes and transaction volumes: Implications for the mixture-of-distributions hypothesis. Econometrica: Journal of the Econometric Society, 305-321.

FILIMONOV, V., BICCHETTI, D., MAYSTRE, N. \& SORNETTE, D. 2013. Quantification of the high level of endogeneity and of structural regime shifts in commodity markets. Journal of International Money and Finance.

GALLOWAY, T. M. \& KOLB, R. W. 1996. Futures prices and the maturity effect. Journal of Futures Markets, 16, 809-828.

GARMAN, M. B. \& KLASS, M. J. 1980. On the estimation of security price volatilities from historical data. Journal of business, 67-78.

GILBERT, C. L. 2010. How to understand high food prices. Journal of Agricultural Economics, $61,398-425$.

GOODWIN, B. K. \& SCHNEPF, R. 2000. Determinants of endogenous price risk in corn and wheat futures markets. Journal of Futures Markets, 20, 753-774.

GOUEL, C. 2012. Agricultural price instability: A survey of competing explanations and remedies. Journal of Economic Surveys, 26, 129-156.

GRAMMATIKOS, T. \& SAUNDERS, A. 1986. Futures price variability: a test of maturity and volume effects. Journal of Business, 319-330. 
HEDEGAARD, E. 2011. How margins are set and affect asset prices. Job Market Paper, New York University.

JAVAHERI, A., WILMOTT, P. \& HAUG, E. G. 2004. GARCH and volatility swaps. Quantitative Finance, 4, 589-595.

JOHNSON, J. 1998. Does the Samuelson effect hold for SPI futures. Department of Accounting and Finance, University of Western Australia, Working Paper.

KALEV, P. S. \& DUONG, H. N. 2008. A test of the Samuelson hypothesis using realized range. Journal of futures markets, 28, 680-696.

KARALI, B. \& THURMAN, W. N. 2010. Components of grain futures price volatility. Journal of agricultural and resource economics, 167-182.

KENOURGIOS, D. \& KATEVATIS, A. 2011. Maturity effect on stock index futures in an emerging market. Applied Economics Letters, 18, 1029-1033.

KHOURY, N. \& YOUROUGOU, P. 1993. Determinants of agricultural futures price volatilities: Evidence from Winnipeg Commodity Exchange. The Journal of Futures Markets, 13, 345-356.

KOLB, R. W. 1997. Understanding futures markets, Miami, USA, Kolb Publishing Company.

KURUPPUARACHCHI, D. 2015. Efficiency, Risk Premiums and Information Diffusion in Futures Markets: International Evidence. University of Otago.

KYLE, A. S. 1985. Continuous auctions and insider trading. Econometrica: Journal of the Econometric Society, 1315-1335.

LIU, W. H. 2014. Do futures prices exhibit maturity effect? A nonparametric revisit. Applied Economics, 46, 813-825.

MADARASSY, R. 2003. Maturity effects in futures markets: evidence from eleven financial futures markets. UC Santa Cruz Economics Working Paper.

MILONAS, N. T. 1986. Price Variability and the Maturity Effect in Futures Markets. Journal of Futures Markets, 6, 443-460.

MILONAS, N. T. 1991. Measuring seasonalities in commodity markets and the half-month effect. The Journal of Futures Markets, 11, 331-345.

MORGAN, W., COTTER, J. \& DOWD, K. 2012. Extreme measures of agricultural financial risk. Journal of Agricultural Economics, 63, 65-82. 
PARDO, A. \& TORRO, H. 2007. Trading with asymmetric volatility spillovers. Journal of Business Finance \& Accounting, 34, 1548-1568.

PARKINSON, M. 1980. The extreme value method for estimating the variance of the rate of return. Journal of Business, 53, 61-65.

PWC 2012. An African perspective valuation methodology survey 2012. PricewaterhouseCoopers publication. Retrieved on 2 November 2014, http://www.pwc.co.za/valuation-survey.

ROLL, R. 1984. A simple implicit measure of the effective bid-ask spread in an efficient market. The Journal of Finance, 39, 1127-1139.

RUTLEDGE, D. J. 1976. A note on the variability of futures prices. The Review of Economics and Statistics, 118-120.

SAFCOM 2013. IMR methodology review for the equity derivatives market. SAFEX Clearing Company (Pvt) Ltd. SAFCOM publication, Johannesburg Stock Exchange, Johannesburg, South Africa, 1-17.

SAMUELSON, P. A. 1965. Proof that properly anticipated prices fluctuate randomly. The Industrial Management Review, 6, 41-49.

SEGALL, J. 1956. The effect of maturity on price fluctuations. The Journal of Business, 29, $202-$ 206.

SERLETIS, A. 1992. Maturity effects in energy futures. Energy Economics, 14, 150-157.

TADESSE, G., ALGIERI, B., KALKUHL, M. \& VON BRAUN, J. 2013. Drivers and triggers of international food price spikes and volatility. Food Policy.

TELSER, L. G. 1956. The supply of stocks: cotton and wheat. University of Chicago, Department of Economics.

VENKATESWARAN, M., BRORSEN, B. W. \& HALL, J. A. 1993. The distribution of standardized futures price changes. Journal of Futures Markets, 13, 279-298.

VILJOEN, C. 2004. Price discovery, price behaviour, and efficiency of selected grain commodities traded on the agricultural products division of the JSE securities exchange. Doctor of philosophy thesis, Rhodes University.

WARSHAWSKY, M. J. 1989. The adequacy and consistency of margin requirements: The cash, futures and options segments of the equity markets. Review of futures Markets, 8, 420437. 


\section{Table 1: Contracts descriptive information}

\begin{tabular}{lccccc}
\hline Commodity & Beginning & End & Observations & $\begin{array}{r}\text { Maturity } \\
\text { months }\end{array}$ & $\begin{array}{r}\text { Year of } \\
\text { Listing }\end{array}$ \\
\hline Agricultural commodities & & & & & \\
White maize & $01 / 04 / 1997$ & $22 / 12 / 2014$ & 4425 & $3,5,7,9,12$ & 1997 \\
Yellow maize & $01 / 04 / 1997$ & $28 / 11 / 2014$ & 4416 & $3,5,7,9,12$ & 1997 \\
Wheat & $01 / 01 / 1999$ & $23 / 09 / 2014$ & 3937 & $3,5,7,9,12$ & 1997 \\
Metals commodities & & & & \\
Silver $\quad 14 / 12 / 2010$ & $19 / 12 / 2014$ & 995 & $3,6,9,12$ & 2010 \\
Energy commodities & & & & \\
\multicolumn{2}{l}{ WTIO } & & & & \\
\hline
\end{tabular}

Descriptive information on the contracts in this study is presented in the table. The months January,...., December are represented under the column "Maturity months" as respectively $1, \ldots, 12$. Contracts are categorized as agricultural, metals and energy contracts. 
Figure 1: Graphs on price and return series by commodity
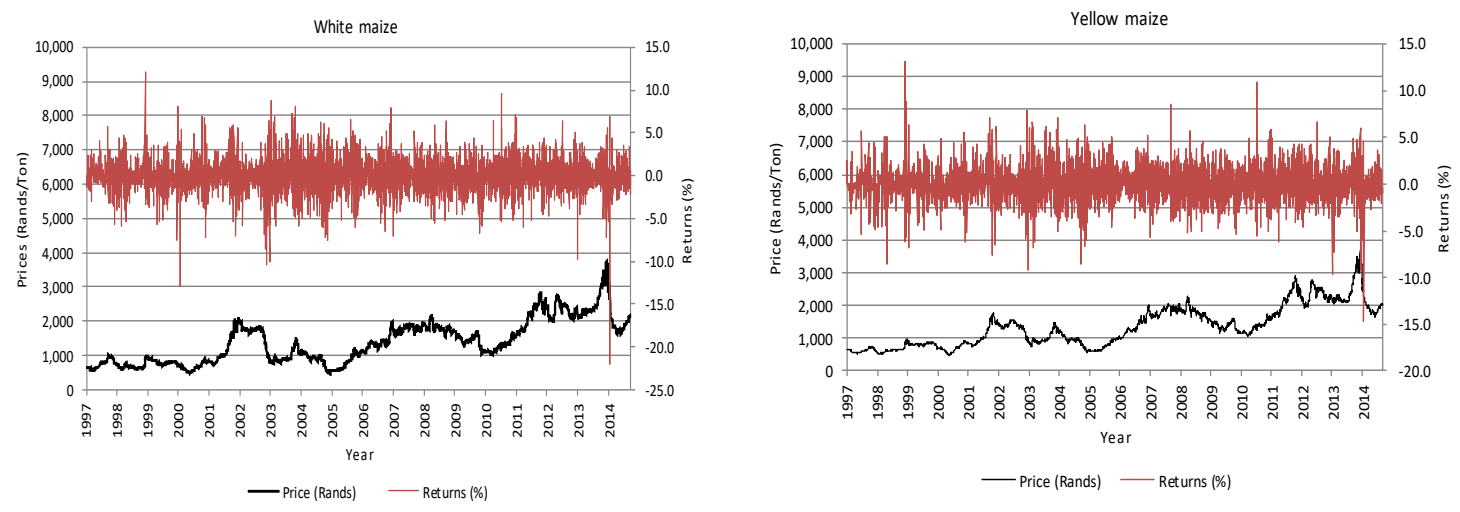

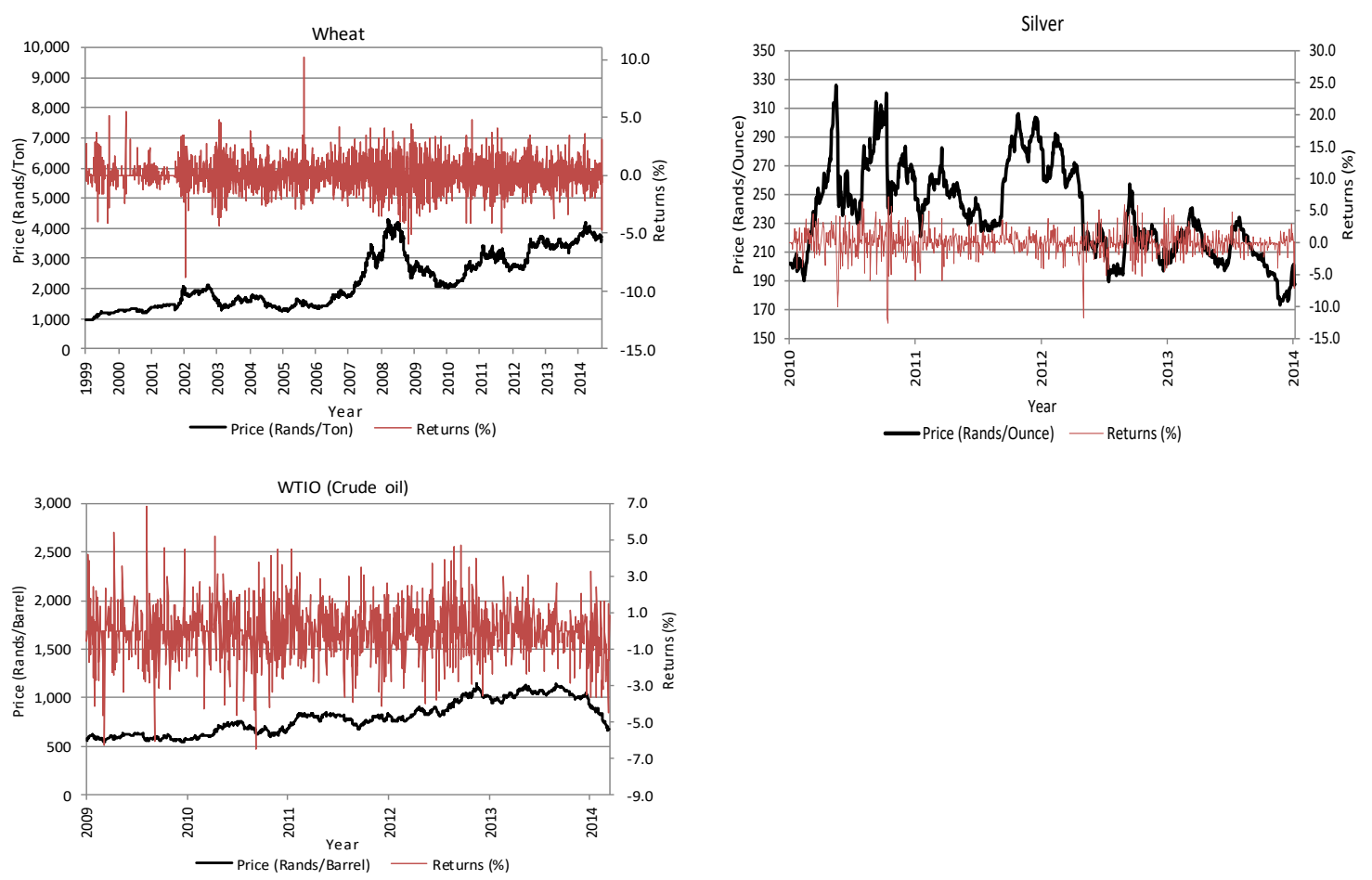

Graphs for the daily price and returns series for white maize, yellow maize, wheat, silver and WTIO crude traded on SAFEX are presented. Daily contract prices are expressed in Rands and returns are presented in percentage terms. The horizontal axis presents the time period over which data for respective contracts has been collected.

Table 2: Summary Statistics

\begin{tabular}{lrrrrr}
\hline Summary Statistics & W/Maize & Y/Maize & Wheat & Silver & WTIO \\
\hline Panel A: Returns & & & & & \\
Maximum & 12.071 & 13.142 & 10.208 & 7.1824 & 4.6470 \\
Minimum & -10.359 & -14.692 & -8.8831 & -12.611 & -6.4714 \\
Mean & 0.0784 & 0.0659 & 0.0823 & -0.1827 & 0.0155 \\
St. dev & 1.9238 & 1.8169 & 1.2133 & 2.6130 & 1.5013 \\
Skewness & 0.0523 & 0.0212 & 0.1029 & -0.9434 & -0.1141 \\
Kurtosis & 5.1043 & 6.6358 & 6.5992 & 6.6300 & 3.9395 \\
& & & & & \\
Panel B: Volatility $\left(\right.$ VAR $\left._{t}\right)$ & & & & & \\
Maximum & 0.0203 & 0.0160 & 0.0105 & 0.0036 & 0.0058 \\
Minimum & 0.0000 & 0.0000 & 0.0000 & 0.0000 & 0.0000 \\
Mean & 0.0002 & 0.0001 & 0.0001 & 0.0001 & 0.0001
\end{tabular}




\begin{tabular}{lrrrrr} 
St. dev & 0.0005 & 0.0004 & 0.0003 & 0.0003 & 0.0003 \\
Skewness & 22.195 & 17.232 & 22.833 & 7.1369 & 19.069 \\
Kurtosis & 720.50 & 476.88 & 687.66 & 67.315 & 416.54 \\
\# of observations & 3981 & 4071 & 2928 & 271 & 627 \\
\hline
\end{tabular}

Summary statistics for SAFEX futures contract returns and volatility are presented above. For this analysis, daily close-to-close prices have been used to calculate returns which are represented in the table. Sample data for the various contracts commences at different times as shown in Table 1. Panel A shows statistics for the returns set for each contract while Panel B summarizes the volatility measure (by contract) used in the paper. Volatility, similar to Parkinson (1980) is given by:

$$
V A R_{t}=\frac{\left(\ln H_{t}-\ln L_{t}\right)^{2}}{4 \ln 2}
$$

Table 3: Test for maturity effects using daily high and low prices

\begin{tabular}{|c|c|c|c|c|c|c|}
\hline Commodity & $\alpha_{0}$ & & ${ }_{1}^{\alpha}$ & & $R^{2}$ & $\overline{A d j . R^{2}}$ \\
\hline White maize & $0.00022^{*}$ & {$[0.0000]$} & -0.00001 & $\begin{array}{l}{[0.3104]} \\
\end{array}$ & 0.0002 & 0.0000 \\
\hline Yellow Maize & $0.00030^{\text {*** }}$ & {$[0.0000]$} & $-0.00005^{* *}$ & [0.0000] & 0.0115 & 0.0112 \\
\hline Wheat & $0.00021^{* * * *}$ & {$[0.0000]$} & $-0.00005^{* *}$ & [0.0000] & 0.0223 & 0.0220 \\
\hline Silver & -0.00002 & [0.6770] & $0.00003^{* *}$ & [0.0406] & 0.0089 & 0.0068 \\
\hline WTIO & 0.08924 & [0.2883] & -0.01934 & {$[0.4562]$} & 0.0007 & -0.0006 \\
\hline
\end{tabular}

Ordinary least squares estimation of volatility is presented, with the daily high-low price volatility estimator. The regression estimated in the table is specified as:

$$
V A R_{t}=\alpha_{0}+\alpha_{1} \ln T T M_{t}+\varepsilon_{t}
$$

P-values are shown in parenthesis. Significance levels at $1 \%, 5 \%$ and $10 \%$ are depicted by $* * *, * *$ and $*$ respectively. 
Table 4: Maturity effect: volume, change in open interest and spread

\begin{tabular}{|c|c|c|c|c|c|}
\hline Description & W/Maize & Y/Maize & Wheat & Silver & WTIO \\
\hline \multicolumn{6}{|c|}{ Panel A: Maturity effect and volume } \\
\hline \multirow[t]{2}{*}{$\beta_{0}$} & 0.00006 & $0.00020^{* * * *}$ & $0.00013^{* * *}$ & $-0.00012^{* * *}$ & 254 \\
\hline & & {$[0.0$} & {$[0.0000]$} & {$[0.0062]$} & 210] \\
\hline \multirow[t]{2}{*}{$\beta_{1}$} & 0.0 & -0.00 & $-0.00004^{* * *}$ & $0.00003^{* * * *}$ & -0.03866 \\
\hline & {$[0.8$} & {$[0.00$} & {$[0.0000]_{* * *}$} & {$[0.0$} & {$[0$} \\
\hline \multirow[t]{2}{*}{$\beta_{2}$} & 0.0 & $2^{* * * *}$ & $0.00001^{* * *}$ & $0.00006^{* * *}$ & 76 \\
\hline & {$[0.1$} & {$[0$.} & {$[0.0000]$} & {$[0.0000]$} & {$[0.4055]$} \\
\hline Adj. $R^{2}$ & 0.00 & 0.0 & 0.0280 & 0.0890 & 0.0002 \\
\hline \multicolumn{6}{|c|}{ Panel B: Maturity effect, volume and change in open interest } \\
\hline \multirow[t]{2}{*}{$\beta_{0}$} & 0.00003 & $0.00019^{* *}$ & $0.00013^{* *}$ & -0.00012 & 0.11170 \\
\hline & {$[0.6$} & {$[0$.} & {$[0.0000]$} & {$[0.00$} & {$[0.3255]$} \\
\hline \multirow[t]{2}{*}{$\beta_{1}$} & -0.00000 & $004^{* * *}$ & $-0.00004^{* * *}$ & $0.00003^{* * *}$ & -0.03962 \\
\hline & & {$[0.0$} & {$[0.0000]$} & {$[0.0108]$} & {$[0.2156]$} \\
\hline$\beta_{2}$ & $0.00003^{* * * *}$ & $0.00002^{* * *}$ & $0.00001^{* * * *}$ & $0.00006^{* * *}$ & 0.01390 \\
\hline
\end{tabular}




\begin{tabular}{llllll} 
& {$[0.0000]$} & {$[0.0005]$} & {$[0.0000]$} & {$[0.0000]$} & {$[0.3685]$} \\
$\beta_{3}$ & 0.00001 & -0.00000 & -0.00000 & 0.00002 & 0.06873 \\
& {$[0.6815]$} & {$[0.9259]$} & {$[0.7691]$} & {$[0.2719]$} & {$[0.3541]$} \\
Adj. $R^{2}$ & 0.0090 & 0.0122 & 0.0272 & 0.0897 & -0.00002 \\
\hline
\end{tabular}

Panel C: Maturity effect, volume, change in open interest and spread

\begin{tabular}{llllll}
$\beta_{0}$ & $-0.00016^{* * * *}$ & 0.00003 & 0.00005 & $-0.00024^{* * * *}$ & 0.14435 \\
$\beta_{1}$ & {$[0.0010]$} & {$[0.4884]^{* * *}[0.1046]^{* * *}$} & {$[0.0007]^{* *}$} & {$[0.2533]$} \\
& -0.00000 & $-0.00003^{* * *}$ & $-0.00004^{* *}$ & $0.00005^{* *}$ & -0.04710 \\
$\beta_{2}$ & {$[0.7925]^{* * *}$} & {$[0.0003]^{* * *}$} & {$[0.0000]^{* *}$} & {$[0.0208]^{* *}$} & {$[0.1839]$} \\
\multirow{3}{*}{$\beta_{3}$} & $0.00003^{* *}$ & $0.00002^{* * *}$ & $0.00001^{* * *}$ & $0.00005^{* * *}$ & 0.00942 \\
& {$[0.0000]$} & {$[0.0018]$} & {$[0.0084]$} & {$[0.0004]$} & {$[0.5851]$} \\
$\beta_{4}$ & -0.00000 & -0.00002 & 0.00000 & 0.00001 & -0.00584 \\
& {$[0.9024]^{* * *}$} & {$[0.1518]^{* * *}$} & {$[0.6914]^{* * *}$} & {$[0.7039]^{* * *}$} & {$[0.9431]$} \\
\multirow{2}{*}{ Adj. $R^{2}$} & $0.00936^{* *}$ & $0.00783^{* *}$ & $0.00754^{* * *}$ & $0.00425^{* * *}$ & -0.04099 \\
\hline
\end{tabular}

Ordinary least squares (OLS) estimation for the influence on volatility of time-tomaturity, traded volume, change in open interest and the bid-ask spread is presented. Panel A introduces time-to-maturity and traded volume while Panel B additionally includes change in open interest. Furthermore, Panel $\mathrm{C}$ introduces an estimator of the bid-ask spread to estimate the relation:

$$
V A R_{t}=\beta_{0}+\beta_{1} \ln T T M_{t}+\beta_{2} \ln V_{t} l_{t}+\beta_{3} \Delta \ln O I_{t}+\beta_{4} S P_{t}+\zeta_{t}
$$

Volatility in the relation is derived from daily high and low prices using Equation (2). The estimator of the bid-ask spread, $S P_{t}$ is derived using daily high and low prices. P-values are shown in parenthesis. Significance levels at $1 \%, 5 \%$ and $10 \%$ are depicted by $* * *, * *$ and $*$ respectively.

Table 5: Cross-correlations: volume, open interest, spread

\begin{tabular}{llllll}
\hline Description & \multicolumn{3}{l}{$\ln \mathrm{Vol}_{t}$} & \multicolumn{3}{l}{$\Delta \operatorname{lnOI}_{t}$} & \\
\hline White maize & $\Delta \operatorname{lnOI} I_{t}$ & $0.04510^{* * * *}$ & {$[0.0047]$} & 1.00000 & \\
& $S P_{t}$ & $0.06290^{* * *}$ & {$[0.0001]$} & $0.03270^{* * *}$ & {$[0.0406]$} \\
\hline Yellow maize & $\Delta \operatorname{lnOI} I_{t}$ & 0.01620 & {$[0.3238]$} & 1.00000 & \\
& $S P_{t}$ & 0.01010 & {$[0.5381]$} & $0.06610^{* * * *}$ & {$[0.0001]$} \\
\hline Wheat & $\Delta \operatorname{lnOI} I_{t}$ & $0.07390^{* * *}$ & {$[0.0002]$} & 1.00000 & \\
& $S P_{t}$ & $0.06250^{* * *}$ & {$[0.0014]$} & -0.02970 & {$[0.1281]$} \\
\hline Silver & $\Delta \operatorname{lnOI} I_{t}$ & $-0.09530^{* * *}$ & {$[0.1189]$} & 1.00000 & \\
& $S P_{t}$ & $0.31990^{* * *}$ & {$[0.0000]$} & 0.06510 & {$[0.2873]$} \\
\hline WTIO Crude & $\Delta \operatorname{lnOI} I_{t}$ & $-0.12850^{* * *}$ & {$[0.0013]$} & 1.00000 & \\
& $S P_{t}$ & 0.04360 & {$[0.2755]$} & -0.05620 & {$[0.1600]$} \\
\hline
\end{tabular}


The table shows cross-correlations among traded volume, change in open interest and bid-ask spread. $S P_{t}$ represents bid-ask spread generated using the estimator in Corwin and Schultz (2012). As there are significant cross-correlation coefficients, the need arises for modifying estimations to account for the impact of multicollinearity. Pvalues are shown in parenthesis. Significance levels at $1 \%, 5 \%$ and $10 \%$ are depicted by $* * * * *$ and $*$ respectively.

Table 6: Maturity effect: traded volume, residuals of change in open interest, spread

\begin{tabular}{|c|c|c|c|c|c|}
\hline Description & W/Maize & Y/Maize & Wheat & Silver & WTIO \\
\hline \multirow[t]{2}{*}{$\overline{\beta_{0}}$} & 0.00000 & $0.00017^{* * *}$ & $0.00014^{* * *}$ & $-0.00017^{*}$ & 0.14317 \\
\hline & [0.9758] & {$[0.0000]$} & {$[0.0000]$} & {$[0.0184]$} & {$[0.2570]$} \\
\hline \multirow[t]{2}{*}{$\beta_{1}$} & -0.00000 & $-0.00003^{* * * *}$ & $-0.00004^{* * *}$ & $0.00005^{* *}$ & -0.04710 \\
\hline & {$[0.7925]$} & [0.0003] & {$[0.0000]$} & {$[0.0208]$} & [0.1839] \\
\hline \multirow[t]{2}{*}{$\beta_{2}$} & $0.00003^{* * *}$ & $0.00002^{* * * *}$ & $0.00001^{* * * *}$ & $0.00008^{* * *}$ & 0.00948 \\
\hline & {$[0.0000]$} & {$[0.0011]$} & [0.0005] & {$[0.0000]$} & {$[0.5810]$} \\
\hline \multirow[t]{2}{*}{$\beta_{3}$} & 0.00001 & -0.00000 & 0.00000 & 0.00003 & -0.00530 \\
\hline & {$[0.5822]$} & {$[0.8230]$} & {$[0.9214]$} & {$[0.2531]_{* *}$} & [0.9481] \\
\hline$\beta_{4}$ & $0.00936^{* * * *}$ & $0.00783^{* * *}$ & $0.00754^{* * * *}$ & $0.00425^{*}$ & -0.04099 \\
\hline
\end{tabular}




\begin{tabular}{llllll} 
& {$[0.0000]$} & {$[0.0000]$} & {$[0.0000]$} & {$[0.0000]$} & {$[0.9244]$} \\
Adj. $R^{2}$ & 0.1247 & 0.0940 & 0.0956 & 0.2674 & -0.0036 \\
\hline
\end{tabular}

Presented in the table is ordinary least squares (OLS) estimation for the influence on volatility of time-to-maturity, traded volume and residuals from the change in open interest and bid-ask spread relations. The model estimated is:

$$
V A R_{t} \beta={ }_{0} \beta+_{1} \ln T_{T M} \beta+_{2} \ln V o l_{t} \beta{ }_{3} \hat{\varepsilon} \hat{\varepsilon}_{1, t} \beta+_{4} \hat{\varepsilon}_{2, t} v+_{t}
$$

Residuals for change in open interest and bid-ask spread are respectively, ${ }_{1, t} \hat{\varepsilon}_{2, t}$.

Volatility in the relation is derived from high and low prices using Equation (1). Pvalues are shown in parenthesis. Significance levels at $1 \%, 5 \%$ and $10 \%$ are depicted by $* * *, * *$ and $*$ respectively.

Table 7: Maturity effects - accounting for multicollinearity and seasonality

\begin{tabular}{|c|c|c|c|c|c|}
\hline \multirow[t]{2}{*}{ Description } & W/Maize & Y/Maize & Wheat & Silver & WTIO \\
\hline & ${ }_{0} \beta-0.00029 *$ & ${ }^{* *}-0.00009^{*}$ & 0.00001 & $-0.00028^{*}$ & 0.09291 \\
\hline & {$[0.0000]$} & {$[0.0262]$} & {$[0.8$} & 340] [0 & [0.4570] \\
\hline \multirow{2}{*}{]$\left._{l} \beta\right] 0.0775$} & $0.00002^{*}$ & -0.00001 & -0.00002 & 0.00006 & -0.04008 \\
\hline & & {$[0.5136]$} & {$[0.0$} & 30 & ] [0.2529] \\
\hline 2 & $0.00004^{* * *}$ & $0.00002^{* * *}$ & $0.00001^{* * * *}$ & $0.00007^{* * * *}$ & 0.00893 \\
\hline$\beta$ & {$[0.0000]$} & {$[0.00$} & {$[0.00$} & {$[0.0$} & {$[0$.} \\
\hline$\rho$ & 0.00001 & 0.00000 & 0.00000 & 0.00003 & -0.01912 \\
\hline$\beta$ & {$[0.5769]$} & {$[0.9657]$} & {$[0.7795]$} & {$[0.2478]$} & {$[0.8127]$} \\
\hline & $0.00847^{*}$ & $0.00706^{*}$ & $0.00740^{* * * *}$ & $0.00373^{* * * *}$ & -0.02590 \\
\hline & [0.0000] & [0.0000] & [0.0000] & {$[0.0000]$} & [0.9516] \\
\hline Adj. & 0.1112 & 0.0789 & 0.0851 & 0.2618 & 0.0031 \\
\hline
\end{tabular}


Ordinary least squares (OLS) estimation of maturity effects is presented. Seasonality at the daily and monthly levels is taken into account by way of dummy variables. The seasonality relation is:

$$
V A R_{t}=\alpha+\sum_{i=2}^{5} \delta_{i} D_{i, t}+\sum_{m=2}^{12} \theta_{m} M_{m, t}+\xi_{t}
$$

Residuals $\varepsilon_{t}$ are saved as the new volatility series $n v_{t}$. The relation estimated in this table is:

$$
n v_{t}=\beta_{0}+\beta_{1} \ln T T M_{t}+\beta_{2} \ln V o l_{t}+\beta_{3} \hat{\varepsilon}_{1, t}+\beta_{4} \hat{\varepsilon}_{2, t}+\eta_{t}
$$

Residuals derived from change in open interest, and bid-ask spread are respectively represented as $\hat{\varepsilon}_{1, t}$ and $\hat{\varepsilon}_{2, t}$. P-values are shown in parenthesis. Significance levels at $1 \%, 5 \%$ and $10 \%$ are depicted by $* * *, * *$ and $*$ respectively.

${ }^{\mathrm{i}}$ Market depth is defined in Madarassy (2003) as order flow capable of moving financial asset prices by one unit.

${ }^{i i}$ Contract maturities occur on SAFEX in the months of March, May, July, September and December.

iii These products became popular in US markets in the aftermath of the Long Term Capital Management financial crisis. 